Here the new mechanism comes in. This vertical axis supports a sort of bracket, $\mathrm{P}$, to the extremity of which is attached a small bead or ball, $\mathrm{B}$, by means of a thread a few centimetres long. Putting out of view meantime the other parts resting on the case, it will be seen that the axis, by the action of the main spring, will turn with a rapid movement, drawing the ball $\mathrm{B}$ along with it. To regulate this movement, it is sought to interpose in its path suitable obstacles; this is the object of the horizontal wire terminating in the hooks $\mathrm{T}$, and of the vertical pillars fixed on the case. The bracket $P$ draws the thread in its movement and makes it strike against the arm ' $\mathrm{T}$; it is thus arrested, and by virtue of its acquired speed, the ball B winds the thread around the pillar on the left; then follows an unwinding of the thread and a rewinding in an inverse direction, which enables the thread to pass the point $T$. But in unwinding it strikes a second time against the pillar, winds and unwinds anew, and only

\section{A CLOUD-GLOW APPARATUS}

$\mathrm{B}^{\mathrm{y}}$ the kindness of Prof. J. Kiessling, of Hamburg, we illustrate a simple and easily arranged piece of apparatus which he has designed for the purpose of exhibiting on an experimental scale some of the many colour-phenomena which are produced when direct sunlight, or electric light, penetrates a moist or a dry cloud. In particular the apparatus can be used to produce on an artificially excited mist the same kinds of intense colorations which were visible in such extraordinary brilliancy in the winter $1883^{-84}$ during the hours of twilight at almost every place the whole world over.

The following pieces compose the apparatus:-

I. A glass globe, A, Fig. I, holding about 20 litres, fixed succeeds in passing this double obstacle after four successive windings, twice in one direction, and twice in the opposite direction around the same pillar. The thread thus set at liberty permits the bracket to turn $\mathrm{I} 80^{\circ}$ around the vertical axis. After this rotation it encounters two analogous objects placed on the right of the clock, and is delayed a certain time before passing these objects and returning to the pillar on the right. By suitably varying the length of the thread, which is easily done by means of a runner on the bracket, we obtain the complete phase of the movement with its eight successive windings of the thread, lasting exactly six seconds; and the clock is thus regulated, if not with all the precision of a chronometer, with an approximation said to be sufficient for ordinary use. The principle applied in this clock might possibly be utilised in cases where it is sought to regulate a slow movement of rotation by simple arrangements, both economical and uncumbrous.

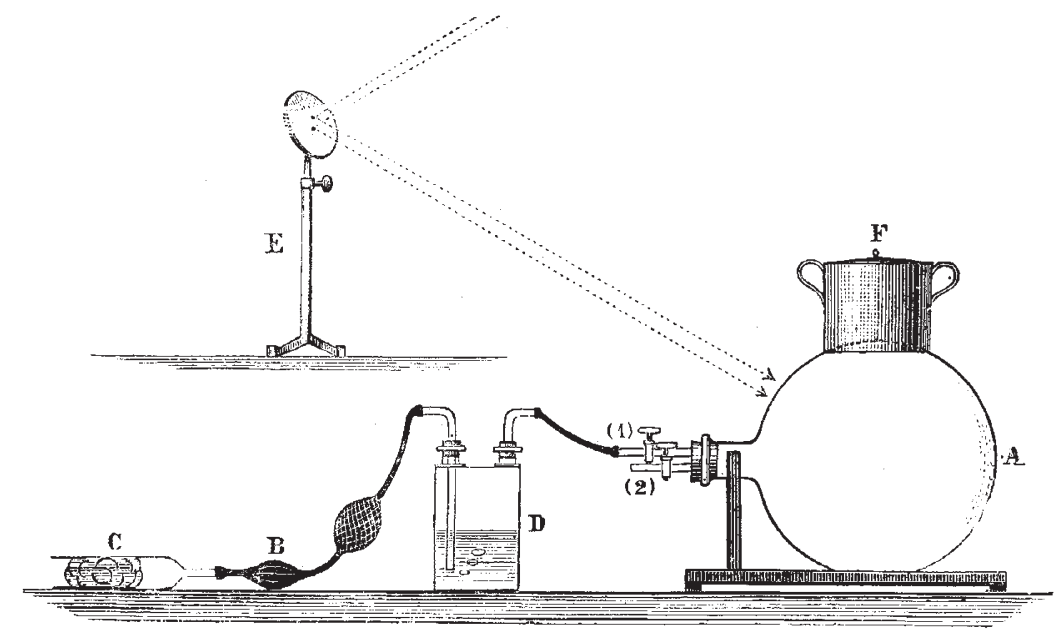

lowering of the temperature, and the production of a tolerably homogeneous mist, the density of which will depend on the quantity of aqueous vapour present.

4. A simple heliostat, $E$, consisting of a mirror capable of being turned either in altitude or azimuth on an iron stand, and also of being clamped at any desired height.

5. A Woulff's wash-bottle, D. This can be filled with hot water so as to yield a supersaturated atmosphere ; or, by the addition of ammonia or of hydrochloric acid, may furnish vapours of these materials for experiment in the globe.

6. A cylindrical tin-ware vessel, $\mathrm{F}$, with a spherical bottom, to be set upon the glass globe, to heat or cool it as may be desired.

The following experiments may be made with this apparatus :- in a wooden support, and closed by a rubber stopper bored with two holes. Through these holes enter two tubes of glass (I) and (2), with taps ground in.

2. An air-filter, $\mathrm{C}$, consisting of a glass tube 30 centimetres long, filled with cotton-wool.

3. An india-rubber pump, $\mathrm{B}$, for producing spray or mist. This is simply part of a common spray-apparatus, and is set so that it draws air from the air-filter and delivers it into the globe. By this means a pressure of one-sixth to one-fifth of an atmosphere is readily obtained. Suppose 15 or 20 grammes of water to have been introduced into the globe and such a pressure to have been produced, and then after about IO-I 5 seconds the other tap (2) to be suddenly opened, or removed quite out of the tube, the release of pressure will result in a sudden

[I] The Ordinary Lunar Halo. First cover the surface of the mirror with a card disk having a central circular opening 2 centimetres in diameter, covered with tissue paper. In direct sunlight observe the bright surface of this circle of tissue paper (which serves as an artificial moon) through the mist that is produced in the globe by letting in a stream of moist vapour from a flask of hot water for a few seconds. The halo is yellowish with a red-brown edge.

[2] Blue Sun. Pour in to the globe a little hydrochloric acid, and blow in air through the wash-bottle, having filled the latter first with liquid ammonia. A dust-cloud of fine particles of sal-ammoniac is thereby produced. A ray of direct sunlight viewed through this is curiously coloured, appearing at the first moment red, and then changing to bluish violet and to full blue. 
[3] Artificial Cloud-Glow. For producing the intense diffraction colours of the cloud-glow it is necessary to procure a cloud consisting of small particles all about the same magnitude. This is best attained if the air before entering the globe is first led through hot water. If the conditions are favourable the colours are sufficiently intense as to permit of their being received on a white screen one metre distant. 'The colours change rapidly in a regular gradation of order, each colour appearing first at the centre of the field, and moving ouiwards.

Several additional phenomena are to be observed with this apparatus ; and its inventor has devised an ingenious proof of the once-disputed point that the particles of mist are spherules, not vesicles. This he does by showing that certain diffraction phenomena which depend on the size of the particles remain unchanged during a sudden change of external pressure, which, if the particles were bubbles or vesicles, would at oncc cause them to expand.

\section{ILLUMINATION OF MICROSCOPES AND BALANCES}

IN measurements and weighings where high scientific 1 accuracy is needed it is sometimes necessary to use artificial means of illumination, and it is found that when reflected light cannot be conveniently introduced, the heat from ordinary lamps causes variations of the temperature of the room, \&c., which slightly affect the accuracy of the results to bc obtained. By using, however, an incandescent electric lamp fitted inside a glass vesscl of water, the light may be even brought near to the microscope or balance without any appreciable interference with temperature. The glass vessel is provided with a pierced cover or shade, and a little stream of water of a uniform temperature may be kept flowing through the vessel.

By means of a "chromozone" battery, supplied by Mr. O. March, it has been found, at the Standards Office, that a light may be maintained at an insignilicant cost for fifty hours without, of course, any attention. During a recent comparison made by $\mathrm{Mr}$. Chaney of two standard kilogram weights it became neccssary to use the lamp, but the action of the balance was not interfered with by the proximity of the lamp, the probable error of the result being only $\pm 0.005 \mathrm{mgr}$.

\section{NOTES}

IN an ovcrflowing Convocation at Oxfurd, on Tucsday, the battle of viviection was fought out a third time. The victory of souxd sense over false scntiment has again heen won; and on this occasion the vote is unmistakable. In spite of the most vigorous exertions of the opponents of physiology, the decree to endow the Physiological Laboratory-as the other scientific departments in the University are endowed-has been carried by the large majority of one hundred and sixty-eight. The Dean of Christchurch opened the debate in a moderate speech recommending the grant. He pointed out that the vate was for teaching purposes, and in no way concerned viviscction, for Prof. Burdon Sanderson had given the must complete assurances that he would not use painful experiments on living animals for the purposes of traching. Canon Liddon opposed the clecree on the ground that the Council should have introdnced further safeguards against the indiscriminate use of vivisection. He admitted that vivisection was justified in certain casce, and spoke of it as a painful necessity. The Bishop of Oxford denicd the moral right of man to inflict pain in order to advance knowledge, and declared vivisection to be degrading to the sensibility and humanity of thic operator. The vote was supported by Prof. Diccy and Sir W. Anson, ans unintentionally damaged by Dr. Acland. The last speakers were much inter- rupted by a clamour which prevented their remarks being hcard. The announcement of the result-placels, $4 \mathrm{I} 2$; nonplacets, 244-was received with great enthusiasm, both in the arena and in the undergraduates' gallery. It is to be hoped that this decisive vote will put an end to the warfare waged against the teaching of physiology in Oxford.

Georogises throughout the world will be interested to learn that Dr. Franz Ritter von Hauer, who for so many years has so admirably guided the progress of the Geological Survey of Austria, has resigned his post as Director of that institution, and has been appointed Intendant of the Impcrial-Royal Natural History Museum, Vicnna. He carries with him intes his new sphere of labour the hearty good wishes of a large circle of friends and well-wishers, who hope that the official dutics he must now perform will in no way diminish the service he has rendered to science so long and so usefully.

Ir has been proposcd that, for the present session, in place of the formal receptions which have hitherto heen held, the rooms of the Royal Society should be kept open on certain nights in order that Fcllows and their friends may meet together for conversation and for the examination of such objects of interest as may be collected for the occasion. The first of these mectings will take place on Thursday, March 19, fron 7.30 p.m. Any one desirous of showing on that evening any experiments, apparatus, or specimens illustrating any inquiry in which he may be engaged, should communicate with the $\Lambda$ ssistant Secretary, in order that appropriate arrangements may be made.

THE death is announced of the eminent Russian geologist, George Helmersen, at the age of eighty-two. IIe studied at Dorpat under Engelhardt, whom he accompanied on his scientific journey along the course of the Lower Volga and the Ural. IIe subsequently took part in IIofmann's and Humboldt's explorations of the Ural region. Having conpleted his studies, especially in mineralogy, he spent some years, by direction of the Russian $\mathrm{G}$ svernment, in geological travels through Germany, Austria, and Switzerland. In 1835 he joinerl the body of mining cngineers, and was appointed Jirector of Studies at the Mining Institute in St. Petersburg. During leisure periods he carried out a series of important geological journeys over the Kirghiz Steppe, through Norway and Sweden, the coal districts of Poland and Silesia, the mining districts of Lakes Onega and Peipus, and the bituminous coal region in the governments of Kherson and Kiev. He also thoroughly explored the gold mines at Beresovsk, and traced the course which has been fol. lowed in making the Ural Railway. The results of his indefatigahls industry have been publisbed in numerous memoirs of the Russian Academy of Sciences and other works.

We have heard with regret of the untimely dcath of the eminent Russian naturalist, Mr. N. Scvertsoff, which occurred on the evening of January II, when driving across the Don, in the Government of Voronej, his horses and vehicle breaking through the ice. The coachman manager to extricate Mr. Severtsoff, but the thermometer stood at $-10^{\circ}$ Réaumur, and, before he could be taken to a neighbouring village, he was frozen to dcath. It is a singular coincidence that Prof. Fedchenko, anothcr of the greatest of Central Asian naturalists, who, like Mr. Severtsoff, had so often risked his life in the pursuit of science in Turkestan, was alses frozen to death in Europe. Mr. Severtsoff so early as 1867 explored the Thian Shan as far as the sources of the Narin. IIis work on the vertical and horizontal distribution of Turkestan animals was written in Russian, and he has since published uriginal researches on the birds of the Pamir. Certain portions of his remarks on 'Turkestan mammals and birds have been translated, and it is chiclly to him that we are indebted for what information we have in English respecting the mammals, hirds, and reptiles of 